\title{
Mycophenolate Mofetil-Induced Peripheral Neuropathy In The Treatment of Membranous Glomerulonephropathy: A Case Report
}

\author{
Minoo Moghimi ${ }^{1}$, Zahra Nekoukar ${ }^{1}$, and Farhad Gholami ${ }^{1}$ \\ ${ }^{1}$ Mazandaran University of Medical Sciences
}

April 28, 2021

\begin{abstract}
Mycophenolate mofetil (MMF) as an immunosuppressive agent is widely used in the management of Membranous Glomerulonephropathy (MGN). In this report, we describe a 66-year-old male MGN case treated with MMF and revealed acquired sensory-motor axonal polyneuropathy, which is rare and has not been reported before.
\end{abstract}

\section{Hosted file}

Moghimi et al. Manuscript.pdf available at https://authorea.com/users/403273/articles/520012mycophenolate-mofetil-induced-peripheral-neuropathy-in-the-treatment-of-membranousglomerulonephropathy-a-case-report 